\title{
Erratum to: Long-Term Outcome of Rives-Stoppa Technique in Complex Ventral Incisional Hernia Repair
}

\author{
Mostafa Mehrabi · Ali Jangjoo - Hassan Tavoosi • \\ Mahdi Kahrom • Hadi Kahrom
}

Published online: 12 February 2011

(C) Société Internationale de Chirurgie 2011

\section{Erratum to: World J Surg}

DOI 10.1007/s00268-010-0426-3

The Editor-in-Chief of World Journal of Surgery hereby retracts the article entitled, "Long-Term Outcome of Rives-Stoppa Technique in Complex Ventral Incisional
Hernia Repair" by Drs. Mostafa Mehrabi, Ali Jangjoo, Hassan Tavoosi, Mahdi Kahrom, and Hadi Kahrom, in its entirety, which appeared in World J Surg (2010) 34: 1696-1701.

John Hunter, MD Editor-in-Chief, World Journal of Surgery

The online version of the original article can be found under doi:10.1007/s00268-010-0426-3.

M. Mehrabi · A. Jangjoo · H. Tavoosi · M. Kahrom ( $\square)$.

H. Kahrom

Department of General Surgery, Imam Reza Hospital,

Mashhad University of Medical Sciences, Emam Reza Square,

Ebne Sina Avenue, 91995977178 Mashhad, Iran

e-mail: Kahrom@irimc.org 